\title{
Comic Books: A Learning Tool for Meaningful Acquisition of Written Sign Language
}

\author{
Cayley Guimarães ${ }^{1}$, Milton César Oliveira Machado ${ }^{1} \&$ Sueli F. Fernandes ${ }^{2}$ \\ ${ }^{1}$ Academic Department of Design, UTFPR, Curitiba, Brazil \\ ${ }^{2}$ Education Department, UFPR, Curitiba, Brazil \\ Correspondence: Cayley Guimarães, Academic Department of Design, UTFPR, Curitiba, Brazil.
}

\author{
Received: February 1, $2018 \quad$ Accepted: March 8, $2018 \quad$ Online Published: March 20, 2018 \\ doi:10.5539/jel.v7n3p134 URL: https://doi.org/10.5539/jel.v7n3p134
}

\begin{abstract}
Deaf people use Sign Language (SL) for intellectual development, communications and other human activities that are mediated by language - such as the expression of complex and abstract thoughts and feelings; and for literature, culture and knowledge. The Brazilian Sign Language (Libras) is a complete linguistic system of visual-spatial manner, which requires an adequate writing system. The specificities of Libras pose a challenge for alphabetisation/literacy in the educational process of the Deaf, which allows for meaning attribution by the Deaf learner only when the SL is the central pedagogical tool. This process vastly differs from the pedagogical strategies used to teach the written form of the oral languages. The alphabetisation relies heavily on the phoneme-grapheme relations - therefore, not accessible to the Deaf learner. SignWriting is a writing system deemed to be adequate represent Libras, and has been used in literacy processes of Deaf learners. This article presents a visual pedagogical tool, a narrative in the genre of a comic book, to be used for meaningful learning and acquisition of SignWriting. The methodological approach of this research involved the creation of a comic book tool to provide the context and communicational situation where the enunciation in Libras occurs, thus presenting an opportunity to introduce SignWriting. The utterances are then presented in the form of writing activities. Results show that the use of the proposed Visual Narrative approach is an adequate educational strategy to inform the design of pedagogical practices for teaching the writing system of SL.
\end{abstract}

Keywords: sign languages, literacy, visual narratives, writing systems

\section{Introduction}

This research addresses the open research problem of teaching the Deaf to acquire the written form of SL by proposing visual narrative as a learning tool. The proposed tool was designed to be used in both classroom and home environments, thus allowing for richer learning experiences and autonomy. Deaf people have the right to access all human possibilities, such as symbolic communications, social interactions and the use of SL, their natural language. The Brazilian Sign Language (Libras) is of visual-spatial modality, and it is used by the members of the Brazilian Deaf communities for their complex linguistic needs (Fernandes \& Moreira, 2014). Unfortunately, over $90 \%$ of Deaf children are born to non-Deaf parents, who do not know Libras. Thus, the child has no access to Libras, and faces dire consequences in her intellectual and cultural development. An educational process that would provide for the acquisition of Libras at an early infancy would make it possible for the Deaf child to achieve a qualitative development similar to any other child (Ladd, 2003).

Additionally, the Deaf child has difficulties to acquire a Writing System (WS) (i.e., a set of characters used in a sequential way to symbolically represent a language in its utterances, for multiple purposes, such as literature and knowledge creation, among others). It is especially difficult for the Deaf to learn the writing system of the oral language, when one considers that the existing pedagogical methodologies emphasise the relations between the letter and the sound - which is not accessible to the Deaf. The access to a writing system in Libras would represent a leap in the intellectual development process of the Deaf child, given that it would involve the learning of a tool to visually register the sign language in its visual-spatial specificities, without the audiological barriers (Fernandes \& Moreira, 2014). Contrary to popular belief, it is possible to register Libras using a writing system-SL are not restricted to videos, as it is often thought. SignWriting is the most used WS for SL users around the world, and has been successfully used in bilingual educational processes (Sutton, 2006). Writing Systems (i.e., sequences of characters used to symbolically represent a language) serve as support and basis for 
modern society and are considered necessary for the advancement of SL and Deaf culture. The use of writing systems offers ways to record literature, to communicate, to preserve culture, to store and retrieve information, to create science and disseminate knowledge among other activities that value Libras as a language of Culture.

Deaf children have all the human potentialities to become good readers and writers, but, unfortunately, they lack these competencies due to their social conditions that restrict their experiences. They are mostly exposed to methodological processes and cultural products designed and implemented for non-Deaf learners. In order for the Deaf child to acquire the written modality of Libras, there is a need for a natural development of language, intelligence and immersion of the learner in social practices of the written language (Sánchez, 1991; Hoffmeister, 1999). The experiences and methodologies created for the teaching and learning of writing the signs of Libras that are capable to provide the Deaf with adequate education support are few and incipient (Guimarães et al., 2013). There are little to no written texts, with few registered publications created using a writing system of SL, an unfortunate reality that bars the Deaf community from a major component of cultural value. Without written history, it is that much harder for the construction of a Deaf identity within a minority linguistic community (Skliar, 1999). Deaf children should not only have access to knowledge by using the oral language, which is not easily accessible to them - a clear call for the creation of tools in SL (Jonhson, Liddell, \& Erting, 1989).

The challenge to provide tools for the Deaf to have access to WS is complex and urgent, and requires innovative and motivating approaches lest we will be left with an entire community without written history and its memories. According to Vygotsky (1974) reading should contain a myriad of meanings for the learner, otherwise the word is empty; learning to write is equal to learning a new language in all of its social and individual function. It is a literacy process that, more than the simple act of reading and writing, requires an understanding and a use of such skills in society and in the context in which the text is inserted (Lodi, 2002).

This article proposes a pedagogical approach in which literacy is a pleasurable, meaningful learning in which the writing of signs occurs in a situated context of use, mediated by a visual narrative created in the genre of an adapted comic book using SignWriting. The proposed approach is an educational tool that values culture, literature and gives autonomy to the Deaf learner. The remainder of the article discusses the plight of the Deaf, the call for meaningful literacy. Then it presents a general view of the comic book. Internal validation, as well as tests with non-Deaf and Deaf concludes that the proposed approach values Libras as a language of culture.

\section{Literature Review-The Plight of the Deaf}

Born into non-Deaf parents, who do not speak SL, the Deaf does not acquire it. The lack of Libras acquisition prevents the Deaf child to learn daily concepts (McNamara, 1982). Therefore, the child does not learn to ask the necessary questions to clarify her doubts to form relations that would change her cognitive structures. The Deaf has no opportunity to use prior knowledge, to combine it with new one, to infer, to deduce and to create new knowledge, in a mental process that is mediated by communicational, social and linguistic experiences. Language is more than a communication channel (Sánchez, 1991). Language includes a thought regulation function that is essential for intellectual development by allowing the child to first form concrete concepts of the world around her, making sense of it, concepts that later will be the basis from which she would create abstract concepts (Vygotsky, 1974).

The lack of natural language acquisition is detrimental for intellectual development, and results in dire consequences: the inability to perform daily, routine tasks around the family home; the lack of skills for intelligent action; the inability to learn and to plan; the uniquely dystopian dependence solely on the concrete, the visual and the present; the multiple difficulties in socializing, among others. Deaf children grow in a reality in which there is very little material written in Libras (Lodi, 2002). Jonhson, Liddell, \& Erting (1989) argue that it is not enough to present the Deaf with concepts in the oral language and expect her to create concepts in the Deaf Culture, let alone create her own view of the world, her identity.

This monolingual model holds Deaf children back from achieving higher gains when compared to their non-Deaf colleagues. Petito (1994) tells us that the Deaf children have in them and at their disposal all the mechanisms, systems, skills and language acquisition tools, especially the Libras. But, in order to fulfil all their potential, they should be immersed in Libras as their natural language to gain the benefits of intellectual development. Cummings (1984) proposes a theory of interdependency - an interaction between the language of instruction and the type of competence that the child is able to develop in her own language before she enters the formal educational system - the Deaf have less knowledge from which to learn. Nover \& Andrews (1998) tells us that one should offer the Deaf children all the possibilities for them to create their own knowledge, in their own language, which includes the use of a writing system in sign language. Literacy is a process that is highly dependent on meaning creation. 
One considers that the matter of alphabetization continues to be the object of research and reflection in the learning sciences, it is even more so in the field of acquisition of the written modality of the oral language as a second language for Deaf learners, one can imagine the complex challenges of the tasks involving the acquisition, teaching and learning of the written SL (Fernandes \& Moreira, 2014). Even though the theme of writing acquisition is recurrent, and multiple experiences have been developed after the implementation of inclusion policies of the Deaf in regular classrooms, the level of learning and development fail expectations, and are inferior to the non-Deaf children achievements (Allen, 1986). For the Deaf people, the premise of an environment that offers the potential of contact with the symbols of a WS is not a reality.

According to Fernandes \& Moreira (2014), Deaf education requires both the challenge of promoting practices that allow the acquisition and development of SL as a natural tongue. Education should promote the learner with experiences that provide the appropriation of a WS by the Deaf (Cummins, 1984). This should be done using visual channels and not oral-audiological channels as is the case for the non-Deaf children. That is to say, the incursion in the world of writing is not going to happen via the oral methods, but it will occur mediated by visual processes of signification that have the SL at its core.

The social insertion in the natural/mother tongue starts the process of intellectual intelligence of the child and it is, therefore, essential that each child brings to the literacy process her own experiences. In order to make use of such experiences, the educator should understand the manner in which the child learns not only the contents of a given discipline, but they should also incorporate into their pedagogical practices the way in which the child appropriates her own social, cultural and linguistic components (Cagliari, 2000).

The learning environment should make sense and present a context in a way that allows for the collective creation of daily text, which eventually will turn symbolic. Literacy occurs in the mediated interaction. Comprehension and understanding of the text appear in its use - not through mere fragmentation of words, which, out of a context, make no sense. This pedagogical strategy is what offers the multiple possibilities for teaching and learning of reading and writing (Schneuwly, 2002). Vygotsky (1974) tells us about how human behavior is made of sediments of successive layers in which the new layers of knowledge are built based on the previous ones. This can be achieved with visual narratives. Therefore, before the letters, the first knowledge should be that of the word: the text and the context which are possible in the culture in which the child is immersed. There follows a broadening of her view of the world, and her ability to feel, think and act upon such world. The Deaf primary means of gaining knowledge is by the visual experience. Thus, a literacy environment should provide reading and writing activities that are heavily based on visual references in a context where Libras is the language of choice to value culture and promote signification of the meanings that are present in the text. The task of reading the images, along with the actual Libras, will guide the process of reflecting and inferring about the reading of the Libras and its written form.

\subsection{The Importance of a Writing System for Sign Language}

Fischer (2009) tells us that eighty five per cent (85\%) of the world population uses some sort of a WS, which serves as support and basis for the modern, global society. WS are a sequence of symbols that represent a language. They serve many functions: they reproduce speech, thoughts, and abstract concepts among other language related events. WS are a cultural representation of society, as used in literature; they are the utmost tool of human knowledge: WS are necessary for science development; they play a major role in information dissemination in journalism; in many cultures, the calligraphy is an art.

As for the WS of the SL, several authors claim its importance: Martin (1994) considers that WS are more objective and substantial than the oral linguistic communication: they allow for abstract notions; and WS are rooted in the fundamental human need to store and retrieve information for communication with others over time and space. Additionally, Barreto \& Barreto (2012) tell us that WS are used to organize our lives, record our dreams, discoveries and feelings. And Stumpf (2005) tells us that writing fulfils specific functions and meanings that require deliberate analytic actions capable of constructing an intentional structure: writing conveys more than ideas: it represents our way of seeing, feeling and interpreting the world. Written material of Libras should be better explored both as managers of memory, through recording of social enunciation to allow the Deaf, via writing, to keep a more permanent history, less dependent of individual memory.

One can see that WS are important for multiple social functions: they reproduce speech, thoughts and abstract and complex concepts. They are the human tools of knowledge, used for scientific development, information dissemination; they allow for the expression of dreams; they are rooted in the human need to communicate throughout time and space; they help to organize our lives, record ideas, sentiments, discoveries. Writing fulfils human functions and specific meanings, which require analytic and deliberate actions capable of constructing 
internal structures. More than the mere transmission of words, our writing presents to the world our way of seeing, feeling, interpreting and thinking about the world (Stumpf, 2005). The human being should acquire the WS in the moment when she is instigated and directed towards written material, thus making writing a part of a context of functional use of the language, in which the language acquires a character of real meaning.

The Information and Communication Technologies bring new demands on the process that begins by the interpretation of the word "world", as defined by Paulo Freire (1987), and by the comprehension, by the children and their interlocutors of the social function of reading and writing. Deaf learners need to reclaim their voice through Libras use. Thus empowered, they become critical thinkers and problem-solvers, agents of change, capable to "read the word and write the world" and control their social future. Fairclough (1989) adds that it is important to have a critical knowledge of the language use in order to participate and achieve personal and social goals. This should include the learning, also, of a systematic orthography for SL.

Writing is a consequence of the fact that the person knows how to read. He who reads is able to write-readers acquire a writer's code, according to Smith (1983). One of the skills for reading is to decode the WS. The acquisition of the writer's code is contingent on the fact that readers consider themselves to be writers. Hence, a WS for Libras is in direct relation to the Deaf child's thought process, according to Ferreiro \& Teberosky (2008). Therefore, there is a need of a WS for SL that is in direct relation with the process of thinking of the Deaf learner. Such vision of the process is usually associated to alphabetisation: "[...] a necessary condition, although not sufficient, of text comprehension [...]", a step that is not produced without explicit instructions, a process that has positive implications in learning to write. But, it is important to remember that an alphabetisation that is not literacy does not make sense - especially when it comes without a shared cultural knowledge, one of the ways in which the Deaf person uses to search for social inclusion and citizenship rights (Observatoire National de la Lecture, 1998, p. 12). Therefore, it is important to consider that the acquisition of WS and literacy are interconnected: alphabetisation should occur in the context of use and of meanings of social practices of reading and writing, that is to say, of literacy activities, in a process and in a behaviour that is socially valued.

One is wrong to think that SL do not have a writing system, and there is a misconception about the possibilities and the gains of the use of a WS by the Deaf children who speak Libras. Libras is a complete linguistic system, of visual-spatial modality, and requires an adequate WS, capable to map the properties of SL and to linearly represent their spatial and simultaneous expressions. The use of an adequate WS is a process that enhances the linguistic and cognitive skills, thus valuing the identity and the Deaf culture. Unfortunately, the Deaf community had their process of searching and creation of SL and its WS interrupted for over a hundred (100) years. The use of the WS from the oral language, of which the Deaf have little to no understanding, doesn't aid the learning, memorisation, association of knowledge, access to knowledge of other related areas among others. The advantages that reading and writing could offer will exist only if the linguistic code used is naturally accessible (Smith, 1983). There are some proposed WS for SL such as the Mimographie Notation (Bébian, 1825), ELIS (Barros, 2008), the Stokoe notation (Stokoe, 1960), D'Sign (Jouison, 1995), Neve notation (Neve, 1982), HamNoSys (Hanke, 2004), SignWriting (Sutton, 2006), SEL (Lessa-de-Oliveira, 2012) among others. Although these are possibilities, this research focuses on SignWriting.

The incorporation of a WS for Libras (i.e., SignWriting) into the political-pedagogical projects developed in a bilingual context for the Deaf represent a paramount contribution to the dissemination of the Libras and of the Deaf culture. Additionally, such incorporation constitutes a mediating tool for Literacy of the Deaf. Literacy is the resulting process of social practices of the use of the written form as a symbolic system and as a technology, in specific context, for specific goals, to be acquired by the Deaf via a functional use of the language, where language assumes a character of real meaning: therefore, Literacy as effective appropriation is pleasurable, is leisure, is access to information, is communication, is a way to exercise citizenship in different social practices.

From the point of view of the linguistic political planning, the use of the semiotic writing system legitimates the representation of the Deaf culture, as well as the identity ties, given the important role that the dissemination of a writing system takes on the standardisation, lexical enhancement and overall literary and artistic accumulation. In such political and social scenario, a more natural use and dissemination of SignWriting provided by informational tools creates the opportunity for a greater balance in power relations between the Libras and the oral language (Portuguese, in our case) due to historical role of WS in maintaining alive the memory of the language, by incorporation and recording of the collection of human knowledge. From the pedagogical point of view, the current discussion is related to the specificities of the alphabetisation of the Deaf, and how the SignWriting should constitute a mediating element in the appropriation of the writing system. The learning by the Deaf works with the premise that meaning attribution in writing follows from visual and symbolic processes, in which the use of SL takes on a pivotal role. 
However, to realize such premise, there is a need for methodological process that differs from the ones used in teaching the oral language as the maternal language. The current methods do not scaffold the learning by the Deaf, and it takes approximately nine (9) years to alphabetise a Deaf child, according to Stumpf (2005). These latter processes rely on the relations between phoneme and graphemes made by the native speakers, which cannot be achieve by the Deaf. Albeit the several positive aspects related to accessibility and inclusion that the systematization and dissemination of a WS in Libras would bring to the Deaf community, there are very few publications, and the informational tools in SignWriting are precarious. This research uses Libras as a mediating symbolism in the learning of the written text, and use methodological processes to enable the insertion of the Deaf in literacy practices, in the same manner for non-Deaf students, thus contributing to the development of the complex superior psychological functions (e.g., memory, abstraction, generalisation among others) of the Deaf children, in a manner that increases literacy.

\subsection{SignWriting - A Writing System for Sign Languages}

Stokoe (1960) was pioneer in identifying some parameters of the SL, such as hand configuration, location, and orientation of the palm of the hand, local and global movements and non-manual expressions. Sutton (2006) proposes SignWriting as a WS for SL that incorporate these aspects of the language, and it is the most used WS worldwide. The constitutive elements of a sign, articulated with the hands, eyes, parts of the bodies etc. occupy a three-dimensional space, often simultaneously. Therefore, the great challenge is in the form the WS represents each of these elements in space, given that they do not occur linearly as the acoustic signs of the oral languages. SignWriting preserves the three-dimensional characteristics of SL by contemplating various representations for the multiple parameters of the phonology of sign languages. Figure 1 shows how a hand configuration in three different orientations can be written in SignWriting. Some of the SignWriting primitives (akin to letters) are iconic, thus allowing for a good association with the represented sign. As seen in Figure 1, SignWriting allows for spatial representation of SL. Some of the symbols used by SignWriting are very iconic, which allows for a rapid association with the actual sign. The graphemes are presented simultaneously and sequentially, that best suit the nature of the SL-a considerable difference when compared to other WS, which present the graphemes in linear form, in a pattern that follows the logic of the alphabetic writing of the oral languages.

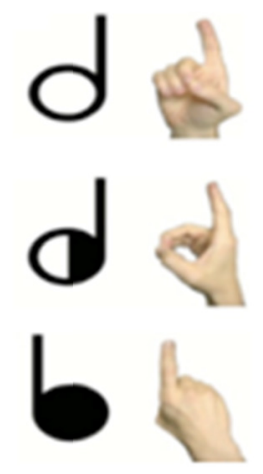

Figure 1. Example of SignWriting: the hand configuration on the right, and its corresponding written form on the left

SignWriting is the most used WS for SL, according to Roald [40]. It is universal (i.e., just like the Latin alphabet is used by many writing system, SignWriting is used by many different SL). SignWriting is based on a pictorial/ideographic representation system, whose organising principle follows visual-spatial significant elements. It is a system conceived to be used by Deaf people in their daily tasks. It serves the same purposes as other WS from oral languages: it can be used to take notes, to read and write books and newspaper, to learning at school, to write contracts, to do research, to create literature etc.), thus making it valuable in real practical use. SignWriting has only recently entered the scientific agenda. Although still incipient, the evidence on the advantages that the incorporation of such writing system would enhance accessibility and social inclusion of the Deaf are undeniable. The current literature points to, at least, two main advantages - related to the political and social recognition of the Deaf community and its natural language. The incorporation of the WS of the Libras (i.e., SignWriting) into the political-pedagogical projects developed in a bilingual context for the Deaf represent 
a paramount contribution to the dissemination of the Libras and of the Deaf culture.

From the point of view of the linguistic political planning, the use of the semiotic WS legitimates the representation of the Deaf culture, as well as the identity ties, given the important role that the dissemination of a writing system takes on the standardisation, lexical enhancement and overall literary and artistic accumulation. In such political and social scenario, a more natural use and dissemination of SignWriting provided by informational tools creates the opportunity for a greater balance in power relations between the Libras and the oral language (Guimarães, Guardezi, \& Fernandes, 2014).

\section{Methods: Visual Narratives-A Meaningful Learning Tool in Sign Language}

The powers of information and knowledge have changed society in uneven and unfair ways. Entire groups and communities have been excluded. Among those excluded we can count the Deaf people (Sorj, 2003; Castells, 2003). The collective intelligence is mediated by language, with the purpose of allowing the citizens to use information to make decisions, solve problems etc. The process of knowledge creation is dependent on the choices society makes (Behar, Bernardi, \& Silva, 2010). To learn via new technologies is an immersive experience that offers opportunities for exploration and for cognitive transformation (Cilela, 2011). The use of such approach should consider the visual manner in which the Deaf acquire knowledge (Felipe, 2007). Oliveira (2017) tells us that educational tools should not merely transpose the traditional form of teaching, where the educator holds all the power, and the learner is a passive receiver of information.

The act of playing is the natural manner in which children manifest themselves, and by recognising such fact, one understands that children are human beings today — not some project into the future. The world experiences are mediated by language: games, painting, dancing etc. that allow for the human being to live their opportunities to comprehend, re-signify and to live with different social and cultural experiences. Therefore, playing is a powerful cultural learning tool. Playing is the time and space where knowledge is transferred. It is fundamental part of human development, and should be valued, with games that are tailored for children, related to their environment.

This way, children are the actors in their own learning (Nicolielo, sommerhalder, \& Alves, 2017). In meaningful learning, Ausubel, Novak, \& Hanesian (1980) consider the previous knowledge of the learner as the most important fact in the teaching and learning process. This way, the new information is combined with the existing one to change cognitive structures, signification and meaning attribution. One does not memorize, but learns by the logic and meaningful signification. According to Cilella (2011), playing is a crucial process in intellectual development, in which one understands ideas, develop skills and assume a social role. Narratives, long used as pedagogical approaches in human education, are powerful tools to convey content, enhance motivation and promote inter-actions (MacNamara, 1982). Social interactions help the learner to internalize thoughts, to create and share knowledge, and to form concrete and abstract thoughts (Vygotsky, 1974). Cognitive management during game playing creates a net of thought strategies used to make sense of the world. Dessaintes (1960) tells us that the situation, the environment, the social interactions and communication channels combine to give form to content and its meaning, leading to intellectual development. The author tells us that nothing is isolated, but everything is always associated to the memories, previous knowledge, memories.

Comic books are part of our everyday lives, and they have been used to promote culture and knowledge. When they are used as pedagogical tools, comic books become more than mere illustration or a means of entertainment: they become a pleasurable tool to enhance communication and understanding. But the usual comic book readily available to the non-Deaf is not accessible to the Deaf. Traditional comic books are characterised by the use of balloons with text representing the story or the utterances of the narrator or the character, and most of them contain text from the oral language (Gomes \& Gomes, 2015). This research advances the state of the art by presenting a comic book in which the characters speak Libras directly - the very nature of Libras allows for the illustration of the characters to sign, in a direct representation of the language (i.e., no balloons).

In order to value Libras in its enunciation and discourse aspects, this research considers it as social, historical and cognitive activity, with communicational role that can be used in the comic book genre, in Libras, to introduce the written form (Oliveira \& Branco, 2015). Toppel, Camargo, \& Chicória (2015, p. 10581) points to multiple advantages of using comic books to teach Physics, for example: "[...] the easy of reading, the information presentation, the illustration and the script make the comic book a fun reading and, at the same time, a rich stimulus for knowledge creation". Our proposed comic book would be classified by the authors as constructivist, due to the fact that it was developed to bring knowledge to the learner. This use is paramount to the autonomy of the Deaf, who can learn in a fun, meaningful way.

The proposed comic book uses the greater iconicity of the sign language to present the lexical, and to present the 
context in which the utterances occur. The visual narrative follows the character to a real situation of use of Libras: the character sends information back to their interlocutors, or speaks Libras with another character. The SignWriting primitives are juxtaposed with the hand of the character. The visual narrative was created in Libras (Bongco, 2000). We next present parts of the comic book in its basics: the context, the communicational situation, the enunciation in Libras, the elements of SignWriting and writing activities. The story begins with the main character, an exploration robot named 5-it poses a mystery: where does it come from? What is it doing? Who sent it? Is it a friend, or is it a threat? All of these elements of the narrative comprise what Sutton-Spence \& Kaneko (2016) would call Deaf Literature: a literature of aesthetically effect, in sign language, in a visual manner that is capable of representing the aspects of the visual culture. Figure 2 shows the robot coming from the space (the mystery remains: is it coming back? From where is it coming? Was it sent by another civilization?).

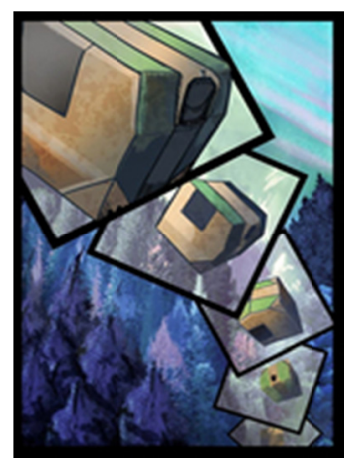

Figure 2. Illustration of the comic book presenting the character-the robot 5-coming from space

The reader sees that it lands and remains still. External circumstances - the fall of part of a tree on the robot, partially shown on Figure 3-the robot is then activated, and begins its journey.

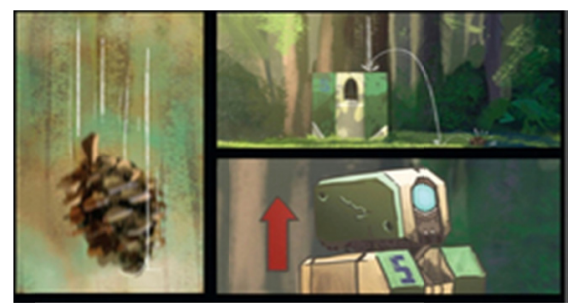

Figure 3. The initial activation of the robot

Thus far, no text has been used. The narrative is solely visual, using non-verbal elements. The robot transforms itself, and starts to walk (it seems that the robot has some pre-determined places to where it wants to go). Eventually, the robot arrives at the Butterfly Sanctuary, shown in Figure 4.

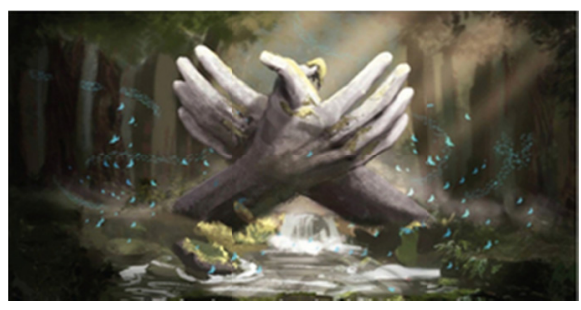

Figure 4. The Sanctuary of the Butterflies 
The reader is left to imagine the purpose of the place: who built it? What is it for? Is there anyone around? Why are there many butterflies? At this time, the educator can explore literacy aspects. This place is related to the butterflies, and it seems to be dedicated to the preservation of them. The monument is a static representation of the Libras sign for BUTTERFLY. At this time, the robot recognises in the monument the Libras sign, and "sees" in its hand the SignWriting primitives. The robot then utters that it has seen the BUTTERFLIES, and signs that to its interlocutors, as seen on Figure 5. As can be seen, the character speaks Libras directly: its illustration is a representation of the sign language. There is no need of a text balloon or any other indication. This is the primary source of reading - the sign language itself.

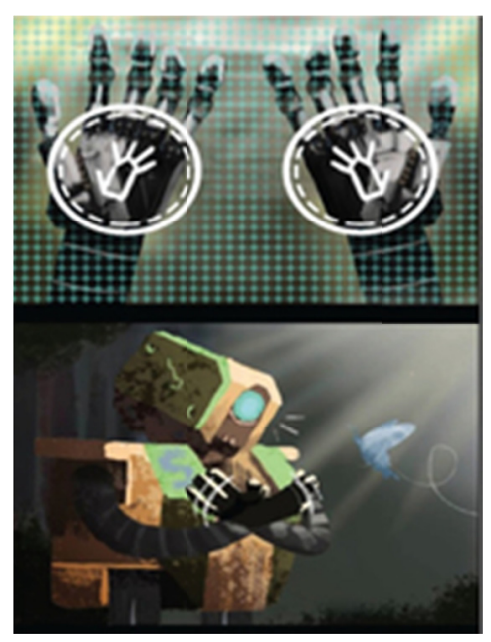

Figure 5. The SignWriting is juxtaposed on the hand of the robot, and the robot utters THE BUTTERFLIES back to its interlocutors

Next, the comic book can present the SignWriting, as shown in Figure 6. This is a second source of reading. The writing is presented in direct association with the uttered sign language.

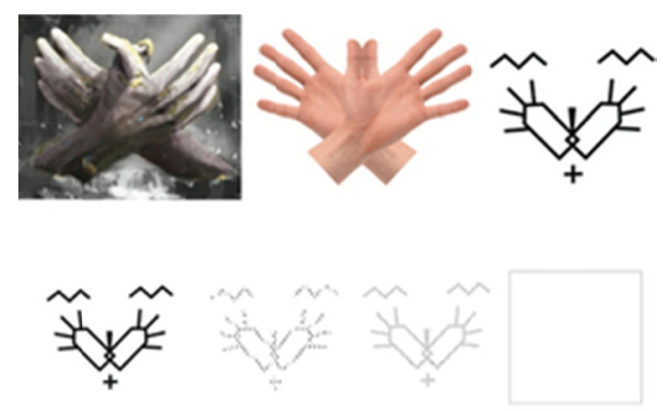

Figure 6. The monument, the sign language for BUTTERFLY, the hand configuration and the SignWriting

The writing is presented in direct association with the uttered sign language. As seen in Figure 6, the sign for BUTTERFLY and its written form are presented. On can also see in Figure 6 the writing activity proposed - the SignWriting becomes dotted, to be filled, and fades away, so that the last box is empty to allow the reader/writer to train and eventually write the sign.

Next, this manuscript presents the general scheme of the design of the comic book to inform the creation of additional material: As the narrative evolves, new communication opportunities appear, as well as new characters, and the utterances become longer and more complex. Figure 7 shows the robot uttering the Libras sentence THE YELLOW BUTTERFLY IS BEAUTIFUL to its interlocutors. 


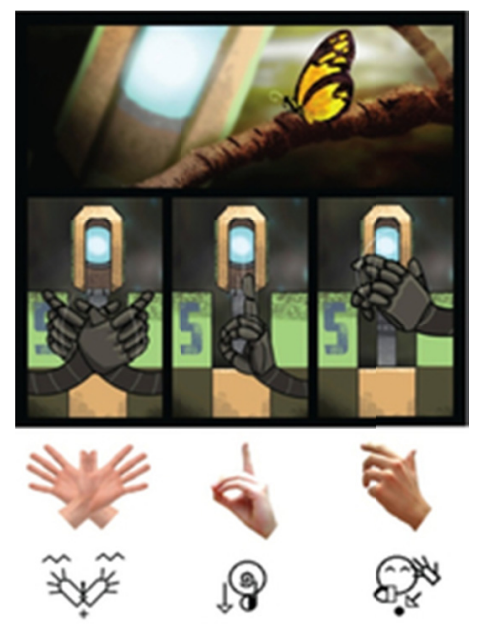

Figure 7. Representation of THE YELLOW BUTTERFLY IS BEAUTIFUL in Libras and in SignWriting

One can see that the comic book presents: the object (the yellow butterfly); then it presents the utterance (the robot is saying "THE YELLOW BUTTERFLY IS BEAUTIFUL); then the comic book shows the hand configuration, and the corresponding SignWriting; and then the comic book proposes a writing activity, taken directly from the utterance in question. Figure 8 shows some illustration studies to represent the Libras signs for SUN and for WAIT.

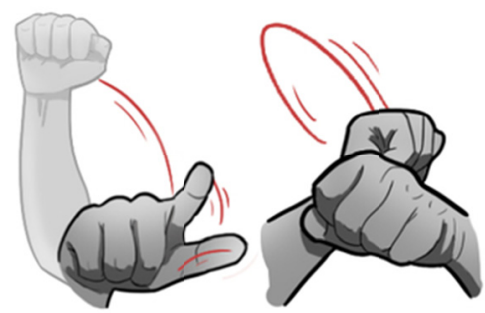

Figure 8. Design studies of the illustration for the signs SUN and WAIT

Figure 9 presents a continuation of the story: the robot encounters a new character, who says HI. The robot is startled by his presence, and retracts. The new character then says he is SORRY.

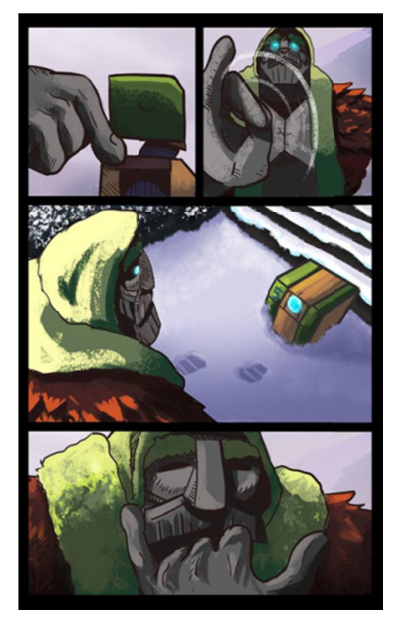

Figure 9. The robot 5 meets another character 
As seen, the proposed learning material uses the actual Libras, with the utterance illustrated in a way that the characters are speaking - as opposed to the usual text ballon found in comic books using the written form of the oral language. The learning material proposed provides an environment where the reader/writer sees the Libras in the paper, rather than in a video - as it is usual for SL materials. This way, the reader/writer has the learning material presented to her in the same media as the one she is going to use to write.

\section{Results: Validations}

The proposed learning material was validated in multiple situations. First, the comic book was internally validated as a pedagogical tool for teaching SignWriting by a group of Deaf educators: the educators were asked whether they thought that the comic book valued Libras, and whether the writing activities were pedagogically sound. Second, 5 non-Deaf students of an undergraduate course of Linguistics/Libras, who knew Libras, were asked to reproduce the utterances in Libras. The students were unanimous in pointing out that the Libras illustrations were very clear, and that they could understand the utterances. They agreed that the comic book was a new way of reading Libras, and that it made sense to see the sign and the written form in the same media.

Additionally, 5 Deaf students of the same undergraduate course of Linguistic/Libras, fluent in Libras, were asked to read the comic book and to perform the writing activities. This activity was conducted for two weeks, two sessions of one hour a week. On the final session, the Deaf readers/writers were asked about the comic book as a tool to value Libras. We summarize, translate and reproduce some of their comments. All the persons participating in the validation process were showed the comic book. They were told about the goal of the comic book and the purpose of the evaluation (i.e., they were told that the object comic book was being evaluated to make improve it). They consented to voluntarily participate.

\subsection{Internal Validation}

First, the research followed the internal validation procedures of Dolz \& Schneuwly (2004), in a multi/interdisciplinary environment. The researchers met for one hour, in the Linguistic/Libras undergraduate teacher's lounge. The evaluators were: a Deaf Psychologist and Educator; a Deaf Professor of SignWriting classes; four Deaf Professors of various disciplines from the course; and a Bilingual Linguist. The subjects appraised the comic book for its theoretical and methodological approach-whether the comic book was consistent from the point of view of effective interlocution with the literature in the area; whether it fulfilled the social relevance criteria and innovativeness of the object proposed.

The participants of the validation considered the comic book as a valid and adequate pedagogical tool for the context of Deaf education both at school and as additional material for the learner to use autonomously. The fact that the robot and other characters speak Libras, and the strategy of using iconic signs from Libras for the first representations were considered important for the first lessons in the process of acquiring not only the SignWriting, but the Libras as well. The educators considered that the enunciations in Libras were contextualised, allowing for easy of understanding and meaning attribution and learning. The strategy of presenting the object, then its utterance, the Libras, the hand configuration and the SignWriting was considered easy to understand - it provides for a complete context of meaningful learning.

\section{Discussions}

\subsection{Importance and Possibilities of Application of the Learning Material}

The importance and possibilities of application of the learning Material can be seen by the validation: the researchers met with 5 Deaf and 5 non-Deaf students from the linguistic/Libras course, who are training to become educators after graduation. They were asked to evaluate the proposed comic book considering its importance, and applicability in the education of the Deaf in a classroom context.

The visual narrative, in the form of a comic book in which the characters spoke Libras was considered very innovative, and had the potential to motivate them to incorporate the tool into their practices. They were unanimous in agreeing that it was very beautifully done, and complete. The utterances were correct; they followed the grammar of Libras and the rules of SignWriting. The writing activities, with the SignWriting being directly related to Libras, in the same media (paper, instead of video). The students considered that the use of dotted lines added to the already ludic aspect of the comic book.

The non-Deaf students found the comic book a very interesting tool. They hadn't realised, prior to seeing the proposed comic book in Libras that the Deaf had no access to the same opportunities to learn-they were accustomed to comic books since childhood, and for most of them comic books were the first reading material they had. It was very much a part of the oral language culture, and they realised that there was no equivalent for the Deaf. They pointed out that the experience was richer than watching a video in Libras, and richer than 
reading a comic book — because the characters were speaking Libras, instead of the balloon with the written oral language.

Some of the Deaf respondents were "[...] happy to see some literature material in Libras". The students felt that it was a good way to have the language and the culture represented: "[...] there are comic books for Cebolinha, Mônica (characters of popular Brazilian comic books). All people can read them, but not the Deaf". The students were happy that "[...] now the Deaf can have a representation in Libras". The Deaf student expressed the importance of the illustration of Libras: "the Deaf use only video. There are only Videos for Libras". The students considered that the proposed illustration of the Libras could provide additional cultural material: "[...] we had no written Libras. Now we learn how to write". The students were unanimous in approving the learning material as a pedagogical tool: "[...] SignWriting is difficult. The robot makes it easy to understand and learn".

After the considerations, the respondents were asked to read and write a sentence. Figure 10 shows the SignWriting of THE YELLOW BUTTERFLY IS BEAUTIFUL, proposed as a writing exercise.

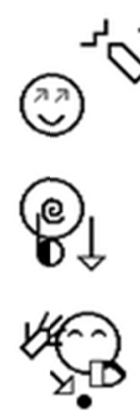

Figure 10. Proposed writing exercise for validation

Figure 10 shows an utterance in SignWriting (THE YELLOW BUTTERFLY IS BEAUTIFUL) that was seen in the comic book. The students had read it and practiced the writing. The students were asked to read the sentence, and then to write it back. All the students were able to read the sentence. And all students were able to write the sentence by copying the proposed sentence. Figure 11 shows an answer by a deaf reader/Writer.

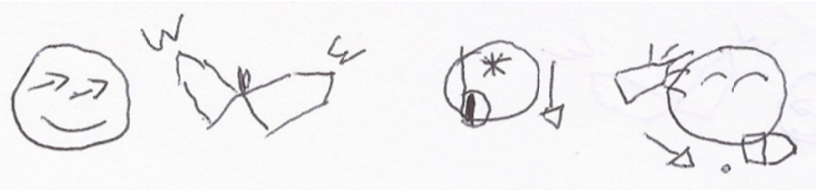

Figure 11. Answer by a deaf reader/writer

Figure 12 shows an answer by a non-deaf reader/writer learner of Linguistic/Libras.

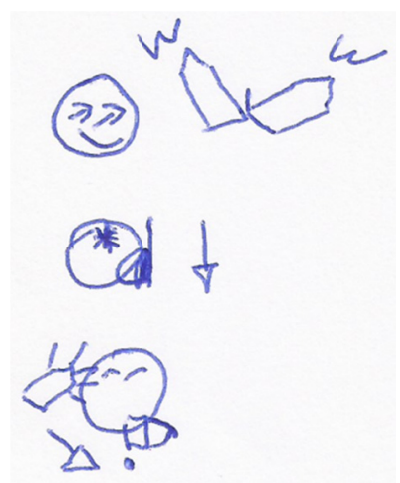

Figure 12. Answer by a non-deaf reader/writer 
As can be seen in Figures 11 and 12 the students were able to read and write the proposed exercise that contained a sentence from the comic book.

\section{Conclusion}

The matter of literacy of the Deaf in Sign Language is a theme that is still open in the applied field of education. It is undeniable the need for a writing system for sign languages, and SignWriting is widely used writing system for Sign Languages. However, there is a lack of research that focuses on the methodological approaches for the Deaf education that allow for meaningful learning, and use the sign language as language of cultural value.

This research innovates and advances the state of the art by presenting a methodological approach that uses visual narratives in the form of a comic book where the characters speak Libras, and then presents the written form of the utterance. Libras is presented in a fictional context, in a visual manner, as an illustration of the characters representing the language. Additionally, the SignWriting is presented, closely following the enunciation, for easy of assimilation and symbolic association between the constitutive parameters of Libras (hand configuration, location etc.) and the graphemes of the written form.

In this new proposed comic book universe, the reader/writer finds an environment that promotes Deaf Literature with which the members of the Deaf community now have not only a comic book that represents their language, but also teaches them. The visual narrative, the manner in which the story is created, and the language is presented, together with the written form of the language and the writing activities were considered an advancement in the field.Such a proposal requires a longitudinal validation process, spanning several opportunities of use by the readers and writers. Additionally, the researchers will create multiple comic books. Those are the main deficiencies of this research, but also its main motivator for future work.

\section{References}

Allen, T. (1986). Patterns of academic achievement among hearing impaired students. In A. Schildroth, \& M. Karchmer (Eds.), Deaf children in America (pp. 161-205). San Francisco, C.A.: College-Hill Press.

Ausubel, D. P., Novak, J. D., \& Hanesian, H. (1980). Psicologia Educacional. Rio de Janeiro: Interamericana.

Barreto, M., \& Barreto, R. (2012). Escrita de sinais sem mistérios [Writing of signs without mystery]. Belo Horizonte: Ed. Autor.

Barros, M. E. (2008). "ELIS—Escrita das Linguas de Sinais" [Writing of sign languages]. 192 f. Ph.D. Thesis. Universidade Federal de Santa Catarina, Florianópolis.

Bébian, R. C. (1825). Mimographie, or essai d'écriture mimique. Paris. Retrieved from http://www.culturasorda.eu/resources/Bebian_mimographie/1825.pdf

Behar, P. A., Bermardo, K., \& Silva, K. A. (2010). Arquiteturas pedagógicas para a educação a distância. Retrieved from http://cinted.ufrgs.br

BRASIL. (2008). Política Nacional de Educação Especial na Perspectiva da Educação Inclusiva [National Policy on Especial Education in the Perspective of Inclusive Education]. Brasília, DF: MEC.

Bongco, M. (2000). Reading Comics: language, culture and the concept of the superhero in comic books. New York, N.Y.: Routledge.

Cagliari, L. C. (1989). Alfabetização e linguística [Alphabetization and linguistic]. São Paulo, S.P.: Scipione.

Castells, M. (2003). A sociedade em rede [The rise of the Network Society]. São Paulo: Paz e Terra.

Cilela, S. (2011). Did you ever know that you're my hero? The power of storytelling. Interactions, VXVIII, 620-666.

Cummins, J. (1984). Bilingual Education and Special Education: Issues in Assessment and Pedagogy. San Diego: College, Hill.

Dessaintes, M. (1960). La construcción par insertion incidente (étude grammaticale et stylistique). [Construction by incident insertion]. Paris: D'Arcy.

Dolz, J., \& Schneuwly, B. (2004). Gêneros orais e escritos na escola [Oral and written genre in schools]. Campinas: Mercado de Letras.

Fairclough, N. (1989). Language and power. New York: Longman Inc.

Felipe, T. (2007). Libras em Contexto: curso básico, livro do estudante [Libras in context: basic course, student book]. Rio de Janeiro: Wallprint Gráfica e Editora. 
Fernandes, S. F. (2006). Práticas de letramento na educação bilíngue para surdos [Literacy practices in bilingual education of the Deaf]. Curitiba: SEED.

Fernandes, S. F. (2012). Educação dos Surdos [Deaf education]. Curitiba, Paraná: IBPEX.

Fernandes, S. F., \& Moreira, L. C. (2014). Bilingual education policies for the Deaf. Educar em Revista, 2, 51-69. https://doi.org/10.1590/0104-4060.37014

Ferreiro, E., \& Teberosky, A. (2008). Psicogênese da Lingua Escrita [Psychogenese of written language]. Porto Alegre: Art Med.

Fischer, S. R. (2009). A history of writing. New York: Reaktion Books.

Freire, P. (1987). Reading the word and the world. Boston: Bergin \& Garvey Publishers Inc.

Gomes, H. J. P., \& Gomes, S. R. P. (2015). História em quadrinhos como ferramenta para o ensino [Comic book as a tool for education] EDUCERE 12. pp. 6818-6830.

Guimarães, C. et al. (2013). Pedagogical Architecture-Internet Artifacts for Bilingualism of the Deaf (Sign Language/Portuguese). 46th IEEE/HICSS, 40-49. https://doi.org/10.1109/HICSS.2013.445

Guimarães, C., Guardezi, J. F., \& Fernandes, S. F. (2014). Sign Language Writing Acquisition-technology for a writing system. 47th IEEE/HICSS, 120-129. https://doi.org/10.1109/HICSS.2014.23

Hanke, T. (2004). HamNoSys. Lisboa, 2004. In O. Streiter \& C. Vettori (Eds.), LREC'04: Representation and processing of sign languages (pp. 1-7). Paris: ELRA.

Hoffmeister, R. (1999). Famílias, crianças surdas, o mundo dos surdos e os profissionais de audiologia. In C. Skliar (Org.), Atualidade da educação bilíngue para surdos [Actualities in deaf education]. Porto Alegre: Mediacao.

Jonhson, R., Liddell, S., \& Erting, C. (1989). Unlocking the curriculum: Principles for achieving access in deaf education. Washington, DC: Gallaudet University.

Jouison, P. (1995). Écrits sur la langue des signes française [Essays on French sign language]. Paris: Harmattan.

Lessa-de-Oliveira, A. S. C. (2017). Libras escrita [Written Libras]. Revista Virtual de Estudos da Linguagem, 10(19), 150-184.

Lodi, A. C. B. (2002). Letramento e minorias [Literacy and minorities]. Porto Alegre: Mediação.

MacNamara, J. (1982). Names for things: a study of human learning. Cambridge, MA: The MIT Press.

Martin, H. J. (1994). The history and power of writing. Chicago: Banton.

Neve, F. X. (1982). Phonologie or gestematique des langue de signes des sourds [Phonologie of sign language]. La Linguistic, 28, 69-93.

Nicolielo, M. E., Sommerhalder, A., \& Alves, J. (2017). Brinquedo e jogos na educacao infantil [Toys and games in childhood education]. Educacao, 42(21), 285-298. https://doi.org/10.5902/1984644422271

Nover, S., \& Andrews, J. (1998). Critical pedagogy in deaf education: Bilingual methodology and staff development. New Mexico: New Mexico School for the Deaf.

OBSERVATOIRE NATIONAL DE LA LECTURE. (1998). Apprendre à lire au cycle des apprentissages fondamentaux [Learn to read]. Ministère de l'Éducation Nationale de la Recherche et de la Technologie. Paris: Éditions Odile Jacob.

Oliveira, P. F. G. M. (2017). Objetos de Aprendizagem de simulacao e animacao para o ensino de Biologia: uma análise quanti-qualitativa [Learning Objects]. Revista Tecnologias na Educacao, 9(19), 10-25.

Oliveira, H. R. A., \& Branco, V. (2015). Práticas de leitura [Reading practices]. Educere, 12, 8270-8283.

Petito, L. (1994). On the equipotentiality of signed and spoken language in early language ontogeny. In D. D. Snider (Ed.), ASL and English literacy: issues, trends and research (pp. 195, 223). Washington, D.C.: Gallaudet University.

Sánchez, C. (1991). La educación de los sordos en un modelo bilingue [Deaf education in a bilingual model]. Mérida: Diakona.

Schneuwly, B. (2002). L'écriture et son apprentissage [Writing and its learning]. Repères, 26(1), 317-329.

Skliar, C. (1999). Atualidade de educação bilingue para Surdos [Current studies in Deaf education]. Porto Alegre: Mediação. 
Sorj, B. (2003).brasil@povo.com. Rio de Janeiro: Jorge Zahar Editor.

Stumpf, M. R. (2005). Aprendizagem de escrita de lingua de sinais pelo sistema SignWriting [Learning written sign language using SignWriting]. Ph.D. Thesis Universidade Federal do Rio Grande do Sul.

Smith, F. (1983). Reading like a writer. Language Arts, 60(1), 558-567.

Stokoe, W. C. (1960). Sign Language structure. Silver Spring. CO: Linstok Press.

Sutton, V. (2006). Lessons in Sign Writing. La Jolla, CA.

Sutton-Spence, R., \& Kaneko, M. (2016). Introducing Sign Language Literature. London: Palgrave. https://doi.org/10.1007/978-1-349-93179-8

Toppel, A., Camargo, S., \& Chicória, T. (2015). Histórias em quadrinhos para o ensino de física [Comic books for teaching physics]. Educere, 12, 10579-10592.

Vygotsky, L. S. (1974). Mind in society. Boston, M.A.: Harvard University Press.

\section{Copyrights}

Copyright for this article is retained by the author(s), with first publication rights granted to the journal.

This is an open-access article distributed under the terms and conditions of the Creative Commons Attribution license (http://creativecommons.org/licenses/by/4.0/). 